Check for updates

Cite this: RSC Adv., 2017, 7, 48913

Received 13th August 2017

Accepted 18th September 2017

DOI: 10.1039/c7ra08957k

rsc.li/rsc-advances

\section{Detoxifying effects of ultrafiltration fractions of Dendrobium aphyllum peptides on chemical and AAPH-induced oxidative stress $\uparrow$}

\author{
Huifan Liu, Juanjuan Ma and Hui Wu (D) * \\ Antioxidative peptides were extracted from Dendrobium aphyllum. The Lactobacillus strain was identified as \\ Lactobacillus amylolyticus L6. Analysis of amino acid composition and HPLC-MS/MS analysis indicated \\ a high antioxidative potential of the low molecular weight DA-P fractions which contained 21 different \\ types of polypeptides. DA-P exhibited antioxidative abilities and the DA-P fraction with a size less than 1 \\ kDa displayed optimal activity, as determined through DPPH and ABTS free radical scavenging assays and \\ the reducing power assay. Human erythrocytes subjected to an 2,2'-azobis[2-methylpropionamidine] \\ dihydrochloride (AAPH)-induced hemolysis assay using the DA-P fraction with the size below $1 \mathrm{kDa}$ \\ quenched the intracellular antioxidant system by inhibiting the generation of reactive oxygen species and \\ malondialdehyde and regulating the activity of cellular antioxidative enzymes, including superoxide \\ dismutase, catalase, and glutathione peroxidase. These results provide valuable information for the use \\ of Dendrobium aphyllum as a functional food for Lactobacillus sp.
}

\section{Introduction}

Peptides are specific small, inactive protein fragments that have the same sequences as their functional proteins. ${ }^{1}$ In general, peptides comprise 2-20 amino acids and have biological activities that depend on their chain length, amino acid composition, and sequence. ${ }^{2}$ The favorable biological activities of peptides include antioxidant, anti-hypertensive, anti-obesity, anticancer, and angiotensin-converting inhibitor activities. ${ }^{3}$ It has been reported that the proportion of hydrophobic groups and aromatic residues in peptides are correlated with their antioxidant activity. ${ }^{4,5}$ For example, the side-chain groups of amino acids such as imidazole in histidine, indolic groups in tryptophan, and phenolic groups in tyrosine have been reported to contribute to the antioxidant activity of peptides. ${ }^{2}$

Reactive oxygen species (ROS) are constantly generated during normal physiological reactions, e.g., defending against infections. ${ }^{6}$ Under conditions of excess ROS or dysfunctions in intrinsic defenses, oxidative stress occurs, leading to protein malformation, DNA damage, membrane phospholipid peroxidation, low-density lipoprotein modification, and aging-related problems, among other issues. ${ }^{7,8}$ Inherent cellular defense systems consist of enzymatic and non-enzymatic antioxidants

College of Food Science and Engineering, South China University of Technology, Department of Food Science and Engineering, Wushan Road 381, Guangzhou, Guangdong, 510640, China. E-mail: fehwu@scut.edu.cn; Fax: +86-20-87112532; Tel: $+86-20-87112853$

$\dagger$ Electronic supplementary information (ESI) available. See DOI: $10.1039 / \mathrm{c} 7 \mathrm{ra} 08957 \mathrm{k}$ that maintain the balance between ROS production and destruction. ${ }^{6}$ Peptides acting as antioxidants can mediate oxidation, including serving as free radical scavengers to directly quench singlet oxygen, chelating metals, synergistic interactions with primary antioxidants, and serving as antioxidative secondary compounds produced by peptides that react with oxidized lipids. ${ }^{9}$ Currently, synthetic antioxidants are effective but exhibit potential health risks following long-term use. ${ }^{10}$ However, natural antioxidants derived from bioactive peptides are easily absorbed because of their low molecular weight; these molecules also show high activity, are inexpensive, and are considered safe. ${ }^{11}$ Methods such as in vitro gastrointestinal chemical digestion, enzymatic hydrolysis, and microbial fermentation can be used to release bioactive peptides from proteins. Compared to digestion and hydrolysis, fermentation is less costly and more eco-friendly and thus is widely used. ${ }^{12}$ In addition, during fermentation, microorganisms can metabolize large molecules in protein sources into smaller ones to elevate the concentration of bioactive components to reduce antinutritional factors and benefit health.

Traditional assays for measuring antioxidant capacity are based on chemical reactions that cannot assess toxicity, bioavailability, and antioxidant component metabolites. In vitro measurement does not consider in vivo situations, such as stability and tissue storage. ${ }^{13,14}$ The use of cell models is a newly developed approach for quantifying the antioxidant capability of bioactive compounds in cell culture, while an AAPH-induced erythrocyte hemolysis assay is used to evaluate AAPH activity as a free radical..$^{15}$ Erythrocytes, which lack a nucleus, produce necessary cofactors through a metabolic network containing 39 metabolites and involving 32 
internal metabolic reactions to defend against oxidative stress and maintain osmotic balance. ${ }^{16,17}$ Under oxidative stress, loss of erythrocyte membrane integrity is caused by lipid peroxidation with peroxyl radicals. ${ }^{18}$ The characteristics of the peptide-mediated detoxification during AAPH-induced erythrocyte hemolysis can be studied by determining the activities of enzymes such as superoxide dismutase (SOD), glutathione peroxidase (GPx), and catalase (CAT) in an enzymatic system, as well as ROS levels, including monodialdehyde (MDA), glutathione (GSH), and glutathione disulfide (GSSG), in a non-enzymatic system. ${ }^{15}$

Plants of the genus Dendrobium, the second largest genus in the Orchidaceae family, are mainly found in tropical and subtropical Asia, Australia, and the Pacific islands and have been used as a source of food and medicine for thousands of years. ${ }^{19}$ Members of this genus contain polysaccharides, proteins, and alkaloids, which have been reported to display anti-cancer, antidiabetic, immunostimulatory, and antioxidative effects. ${ }^{20,21}$ Dendrobium aphyllum is widely cultivated in China, particularly the Yunnan province, because of its low land demand and remarkable commercial value as a functional food source. However, few studies have examined its bioactive compounds.

In this study, we evaluated the presence of antioxidative peptides derived from $D$. aphyllum, verified their antioxidative properties, and explored the underlying mechanism through chemical assays and an AAPH-induced human erythrocyte hemolysis assay.

\section{Materials and methods}

\subsection{Materials}

Dendrobium aphyllum samples were collected from the GAP farm located in Xishuangbanna, Yunnan province, China. These samples were authenticated by experts from the Department of Life Science, South China Agricultural University. Eight strains of Lactobacillus namely Lactobacillus harbinensis (m1), Lactobacillus mucosae 1 (m2), Lactobacillus fermentum 1 (m4), Lactobacillus casei (m8), Lactobacillus rhamnosus (C1), Lactobacillus amylolyticus 5 (L5), Lactobacillus amylolyticus 6 (L6), and Lactobacillus acidophilus ( $\mathrm{mfm}$ ) were obtained from the laboratory of Food Science and Engineering, South China University of Technology. Ultrafiltration cassettes with 1,3 , and $5 \mathrm{kDa}$ molecular weight cut-off sizes were obtained from Millipore Corp (Billerica, MA, USA). Human blood samples were collected from three healthy adult volunteers. Casein, Folin reagent, trichloroacetic acid (TCA), vitamin C (VC), AAPH, DPPH, and ABTS were purchased from Sigma Aldrich (St. Louis, MO, USA). Phosphate-buffered saline (PBS; $\mathrm{pH}$ 7.4) was purchased from Gibco Life Technologies (Grand Island, NY, USA). Kits to determine the activity of SOD, GSH-peroxidase (GSH-PX), CAT, ROS, MDA, GSSG, and GSH were purchased from Beyotime Institute of Biotechnology (Shanghai, China). Other reagents used were of analytical grade.

\subsection{Sample preparation}

The dried stems of $D$. aphyllum were crushed into a powder with a tissue triturator and passed through a 60-mesh screen. Ten grams of collected sample powder was decolorized and watersoluble impurities were removed using $200 \mathrm{~mL} 80 \%$ ethanol by rotating distillation for $4 \mathrm{~h}$, followed by washing with $100 \mathrm{~mL}$ 95\% ethanol, $100 \mathrm{~mL}$ anhydrous ethanol, and $50 \mathrm{~mL}$ anhydrous acetone individually by suction filtration with double filter papers. The $D$. aphyllum powder was dried at $60^{\circ} \mathrm{C}$ and stored at $-20{ }^{\circ} \mathrm{C}$ until further use.

2.2.1 Selection of Lactobacillus for $D$. aphyllum solid-state fermentation. A total of 8 Lactobacillus strains were evaluated during solid-state fermentation. Ten grams of dried D. aphyllum powder was wetted with ultrapure water to maintain 50\% moisture content and sterilization at $121{ }^{\circ} \mathrm{C}$ for $20 \mathrm{~min}$ in an autoclave. The sterile sample was inoculated $(10 \%$ inoculum size) and placed in an incubator at $37{ }^{\circ} \mathrm{C}$ for $48 \mathrm{~h}$. After fermentation, the sample was dried at $60{ }^{\circ} \mathrm{C}$ in an oven and stored at $-20{ }^{\circ} \mathrm{C}$. The detailed process of $D$. aphyllum peptide (DA-P) extraction is described in 2.2.4. Peptide content was measured using Lowry's method. ${ }^{22}$ DA-P yield helped determine whether fermentation by the Lactobacillus strain was satisfactory. The peptide extracted without microbial fermentation was used as a control. Each sample was evaluated in triplicate.

2.2.2 Determination of protease activity during solid-state fermentation. Protease activity was evaluated to determine the dynamic growth pattern of Lactobacillus during fermentation, using the Folin-phenol method of Chinese Standard GB/T 23527-2009 with casein as a substrate. The $\mathrm{pH}$ values of acid proteinase, neutral proteinase, and alkaline proteinase buffer solutions were $3.6,7.5$, and 11 , respectively. The reaction was carried out with $1 \mathrm{~mL}$ enzyme diluent and $1 \mathrm{~mL} \mathrm{2 \%}$ casein for $10 \mathrm{~min}$ at $40{ }^{\circ} \mathrm{C}$ and then $2 \mathrm{~mL} 0.4 \mathrm{M}$ TCA was added to terminate the reaction for $20 \mathrm{~min}$. After centrifugation $(1000 \times$ $g, 10 \mathrm{~min}$ ), a reaction system containing $1 \mathrm{~mL}$ supernatant, $5 \mathrm{~mL}$ $0.4 \mathrm{M} \mathrm{Na}_{2} \mathrm{CO}_{3}$, and $1 \mathrm{~mL}$ Folin reagent was prepared and the absorbance was determined at $680 \mathrm{~nm}$. One unit of enzyme activity was defined as the enzyme content in $1 \mathrm{~mL}$ enzyme solution, which produced $1 \mu \mathrm{g}$ tyrosine by hydrolyzing casein for $1 \mathrm{~min}$ at $40^{\circ} \mathrm{C}$. Each sample was evaluated in triplicate.

2.2.3 Optimization of $D$. aphyllum fermentation conditions by RSM. Single-factor experiments were designed to determine critical factors affecting the extraction yield of DA-P after Lactobacillus solid-state fermentation from D. aphyllum. Four parameters were analyzed, namely fermentation temperature, fermentation time, moisture content, and Lactobacillus inoculum size. Based on the results of single-factor experiments, three critical factors were selected for the design of the response surface experiment, using statistical software. A BoxBehnken design with three factorial points, three levels, and three central points, leading to 15 sets of experiments, was implemented to determine the optimal fermentation conditions for DA-P. ${ }^{23}$ The detailed fermented process is described in 2.2.1 and the detailed extraction process of DA-P is described in 2.2.4. Each sample was evaluated in triplicate.

2.2.4 Exaction of DA-P after fermentation optimization. Based on the results of the response surface experiment, $10 \mathrm{~g} D$. aphyllum powder was fermented by following the procedure under optimized conditions and $1 \mathrm{~g}$ of well-fermented sample was then weighed accurately. DA-P was extracted under the 
following conditions: ratio of material to solvent, $1: 20$; extraction temperature, $37^{\circ} \mathrm{C}$; extraction time, $1 \mathrm{~h}$. The peptide sample was then lyophilized and stored at $-20{ }^{\circ} \mathrm{C}$ until further use.

\subsection{SDS-PAG}

SDS-PAGE was conducted as described by Abeyrathne ${ }^{24}$ with minor modifications. The DA-P sample with or without fermentation was mixed with sample buffer containing $\beta$-mercaptoethanol (ratio of material to solvent, $1: 1$ ). The sample was heated at $95{ }^{\circ} \mathrm{C}$ in a water bath for $5 \mathrm{~min}$ and the supernatant was obtained after centrifugation $(1000 \times g$ for $10 \mathrm{~min})$. Discontinuous vertical plate gel electrophoresis was conducted using a $12 \%$ resolving gel and 5\% stacking gel. Further, $20 \mu \mathrm{L}$ supernatant sample solution and standard proteins were added to the corresponding wells in the stacking gel. For the sample in the stacking gel, a constant voltage of $80 \mathrm{~V}$ was used; resolving gel, 120 V. After electrophoresis, Coomassie Blue G-250 was used to stain the gel for $2 \mathrm{~h}$ and methyl acetate was used for destaining.

\subsection{Ultrafiltration of DA-P}

For further purification, DA-P solution was filtered using an ultrafiltration apparatus as described by Kimatu ${ }^{25}$ with minor modifications. Using 3 different membranes of different sizes, DA-P was separated into four fractions with molecular weights of $<1,1-3,3-5$, and $>5 \mathrm{kDa}$. The four ultrafiltered fractions (UF) were then lyophilized and stored at $-20{ }^{\circ} \mathrm{C}$ until further use. The peptide content of UF was evaluated as described in 2.2.1 and the yield of UF was calculated as following:

$$
\text { UF yield }(\%)=\frac{\text { Peptide weight in UF }}{\text { Peptide weight before ultration }} \times 100 \%
$$

\subsection{Amino acid composition analysis}

The amino acid composition of DA-P peptide and its fractions of different molecular weight were determined using an A300 auto amino acid analyzer (Membra Pure, Bodenheim, Germany) in accordance with the method of You et al. ${ }^{26}$ with minor modification. Total amino acids composition was determined after the hydrolysis at $110{ }^{\circ} \mathrm{C}$ for $24 \mathrm{~h}$ with $6 \mathrm{M} \mathrm{HCl}$ and derivatization with ninhydrin. Free amino acids compositions were determined on the basis of the free amino acids in the supernatant generated through centrifugation $\left(10000 \mathrm{rpm}\right.$ at $4{ }^{\circ} \mathrm{C}$ for 10 $\mathrm{min}$ ) of the precipitate from the mixture (mixing time $1 \mathrm{~h}$ ) of $15 \%$ sulfosalicylic acid $(1 \mathrm{~mL})$ and test samples $(4 \mathrm{~mL})$. Appropriate dilutions of the obtained supernatant and filtration (through $0.22 \mu \mathrm{m}$ filter membrane) were required prior to total and free amino acid analysis. Seventeen amino acid standards were used as external standards.

\subsection{HPLC-MS/MS analysis}

Ultra high-pressure liquid chromatography combined with high-resolution mass spectrometry (Agilent 1290/Brucker maXis impact) was used to characterize the peptides structures in $<1$ kDa DA-P fraction. The chromatography column was an Agilent SB-C18 RRHD column $(1.8 \mu \mathrm{m}, 2.1 \times 50 \mathrm{~mm})$ with a flow rate of $0.2 \mathrm{~mL} \mathrm{~min}^{-1}$ at room temperature. The mobile phase of A was acetonitrile and $\mathrm{B}$ was $0.1 \%$ formic acid water and the scanning wavelength was $220 \mathrm{~nm}$. In terms of acquisition parameter, the source type was ESI with positive ion polarity, the dry heater was set at $180{ }^{\circ} \mathrm{C}$. Initially during scanning, end plate offset was $-500 \mathrm{~V}$ with $50 \mathrm{~m} / \mathrm{z}$ and $4.01 \mathrm{~min}^{-1}$ of dry gas. At the end of scanning, charging voltage was $2000 \mathrm{~V}$ with $1000 \mathrm{~m} / \mathrm{z}$. The injection volume of the sample was $20 \mu \mathrm{L}$.

\subsection{Determination of antioxidant properties}

2.7.1 Estimation of DPPH radical scavenging activity. DPPH radical scavenging activity (DRSA) was assessed as described by Kimatu ${ }^{25}$ with minor modifications. Briefly, $1 \mathrm{~mL}$ of each of the four fractions $\left(0-0.5 \mathrm{mg} \mathrm{mL}^{-1}\right)$ was mixed with $4 \mathrm{~mL}$ DPPH $(0.12 \mathrm{mM})$. The reaction was carried out at $37{ }^{\circ} \mathrm{C}$ for $30 \mathrm{~min}$ in the dark. The DPPH solution without any sample was considered the control and with VC being the positive control. Optical density was determined at $517 \mathrm{~nm}$. DRSA was calculated as follows:

$$
\operatorname{DRSA} \%=\frac{A_{\mathrm{C}}-A_{\mathrm{S}}}{A_{\mathrm{C}}} \times 100
$$

where $A_{\mathrm{c}}$ and $A_{\mathrm{s}}$ are the absorbance values of the control and sample groups, respectively. The DRSA\% of the four fractions was analyzed by comparing the concentration of samples that caused a 50\% reduction in DPPH radical.

Each sample was analyzed in triplicate.

2.7.2 Estimation of ABTS radical scavenging activity. ABTS radical scavenging activity was determined as described by $\mathrm{LuO}^{27}$ with minor modifications. The working solution comprised 7.4 mM ABTS stock solution with an equal volume of $2.6 \mathrm{mM}$ potassium persulfate, and the reaction was carried out for $12 \mathrm{~h}$ in the dark. The absorbance of diluted ABTS working solution in PBS was $0.7 \pm 0.02$ at $734 \mathrm{~nm}$. Further, $0.2 \mathrm{~mL}$ of the four fractions $\left(0-0.5 \mathrm{mg} \mathrm{mL}^{-1}\right)$ and distilled water were added to $2 \mathrm{~mL}$ diluted ABTS working solution as the sample and control, respectively. The reaction was carried out for $6 \mathrm{~min}$ at room temperature in the dark and optical density was determined at $734 \mathrm{~nm}$. ABTS radical scavenging activity was calculated as follows:

$$
\text { ABTS radical scavenging activity } \%=\frac{A_{\mathrm{C}}-A_{\mathrm{S}}}{A_{\mathrm{C}}} \times 100
$$

where $A_{\mathrm{c}}$ and $A_{\mathrm{s}}$ are the absorbance values of the control and sample groups, respectively. All experiments were conducted in triplicate and compared with the unfermented sample.

2.7.3 Estimation of FRAP. The reducing power of DA-P was assessed as described by Moktan ${ }^{\mathbf{1 0}}$ with minor modifications. One milliliter of the four fractions $\left(0-0.5 \mathrm{mg} \mathrm{mL}^{-1}\right)$ was diluted with $2.5 \mathrm{~mL} 0.2 \mathrm{M}$ phosphate buffer. The diluted samples were mixed with $2.5 \mathrm{~mL} 1 \%$ potassium ferricyanide and incubated at $50{ }^{\circ} \mathrm{C}$. After $20 \mathrm{~min}, 2.5 \mathrm{~mL} 10 \%$ TCA was added for $10 \mathrm{~min}$ to terminate the reaction. The reaction solution was mixed with $2.5 \mathrm{~mL}$ distilled water and $1.0 \mathrm{~mL} 0.1 \% \mathrm{FeCl}_{3}$ for $10 \mathrm{~min}$ at room 
temperature. After centrifugation for $10 \mathrm{~min}$ at $1000 \times g$, the optical density of the supernatant was determined at $700 \mathrm{~nm}$. VC was used as the positive control. All experiments were conducted in triplicate and compared with the unfermented sample.

\subsection{Determination of erythrocyte hemolysis induced by AAPH}

2.8.1 Erythrocyte hemolysis assay. Erythrocyte oxidative hemolysis protection of $M_{\mathrm{w}}<1 \mathrm{kDa}$ fraction reduced by AAPH was analyzed as described by Zhang ${ }^{17}$ with minor modifications. All experiments were performed in compliance with "China food safety standards GB151935-2014", and approved by the ethics committee at South China University of Technology. Informed consents were obtained from human participants of this study. Erythrocytes were obtained after three washes with PBS ( $\mathrm{pH} 7.4)$ and centrifugation $\left(1200 \times g, 10 \mathrm{~min}, 4^{\circ} \mathrm{C}\right)$ of blood samples. Erythrocyte suspensions were diluted with 4fold PBS (pH 7.4) and then $200 \mu \mathrm{L}$ erythrocyte suspensions were added to $200 \mu \mathrm{L}$ PBS or $M_{\mathrm{w}}<1 \mathrm{kDa}$ fraction solutions (0-1.5 mg $\left.\mathrm{mL}^{-1}\right)$. The mixture was incubated for $30 \mathrm{~min}$ at $37^{\circ} \mathrm{C}$ and then $400 \mu \mathrm{L} 0.2 \mathrm{mM}$ AAPH was added, followed by incubation for $2 \mathrm{~h}$ with gentle shaking. This mixture was diluted with $3.2 \mathrm{~mL}$ PBS $(\mathrm{pH} 7.4)$ and centrifuged $\left(1200 \times g, 10 \mathrm{~min}, 4{ }^{\circ} \mathrm{C}\right)$. The optical density of the supernatant was determined at $540 \mathrm{~nm}$ for the treated group. Ultrapure water was added to the above suspension to achieve $100 \%$ hemolysis. The hemolysis inhibition rate was calculated as follows:

Hemolysis inhibition rate $\%=$

$$
1-\frac{\mathrm{OD}_{540} \text { of sample treated group }}{\mathrm{OD}_{540} \text { of } 100 \% \text { hemolysis }} \times 100
$$

Three independently replicated determinations were analyzed for each sample.

2.8.2 Scanning electron microscopy (SEM) analysis. Before scanning electron microscopy (SEM) (model 1530VP, LEO, Oberkochen, Germany), the control, AAPH, and AAPH with $M_{\mathrm{w}}<$ $1 \mathrm{kDa}$ DA-P fraction samples were prepared as described by Liao. $^{28}$

2.8.3 Estimation of intracellular ROS level. The erythrocytes were obtained as described by Zhang ${ }^{17}$ with minor modifications, but the supernatant was discarded after 3 washes with PBS (pH 7.4) and erythrocytes were resuspended after dilution in a 5-fold volume of PBS (pH 7.4). Further, $100 \mu \mathrm{L}$ of the erythrocyte resuspension was used to determine the intracellular ROS levels. After centrifugation $\left(1200 \times g, 10 \mathrm{~min}, 4{ }^{\circ} \mathrm{C}\right)$, $200 \mu \mathrm{L}$ of $10 \mu \mathrm{M}$ DCFH-DA was added, followed by incubation for $25 \mathrm{~min}$ at $37{ }^{\circ} \mathrm{C}$ in the dark. The solution was washed and resuspended in $600 \mu \mathrm{L}$ PBS ( $\mathrm{pH}$ 7.4). The fluorescence intensity of erythrocytes was measured with a Fluoroskan Ascent microplate fluorometer (ex/em, 488/525 nm) (Thermo Scientific).

2.8.4 Determination of MDA, GPX, SOD, CAT, GSSG, and GSH. The erythrocytes were obtained as described by Zhang ${ }^{17}$ with minor modifications, but the supernatant was discarded after 3 washes with PBS ( $\mathrm{pH}$ 7.4) and erythrocytes were added to double ultrapure water in an ice-water bath for $10 \mathrm{~min}$ and then centrifuged $\left(1200 \times g, 10 \mathrm{~min}, 4{ }^{\circ} \mathrm{C}\right)$ to obtain the cell lysis buffer. The content of protein, GSH, GSSG, and MDA were determined using bicinchoninic acid, GSH, and microscale MDA kits, respectively. A cellular glutathione peroxidase kit, total superoxide dismutase assay kit, and catalase assay kit were used to determine the activities of GSH-Px, SOD, and CAT, respectively.

\subsection{Statistical analysis}

Data are expressed as the mean \pm standard deviation (SD) of three replicates. Significant differences between the means of parameters were calculated using Duncan's multiple-range test using SPSS 17.0 software (SPSS, Inc., Chicago, IL, USA). A $P$ value less than 0.05 was considered statistically significant.

\section{Results and discussion}

\subsection{Strain determination of Lactobacillus on solid-state fermentation}

In this study, 8 species of Lactobacillus, which are known to be safe strains, were used in fermentation of D. aphyllum and the peptide levels after fermentation and those extracted under the same conditions are shown in Fig. 1A. Compared to the control group $(7.82 \pm 0.57 \%)$, all strains fermented showed increased peptide content, with $L$. amylolyticus L6 showing the best results $(17.85 \pm 0.54 \%)$. L. amylolyticus is widely used in foods processing. L. amylolyticus L6, which has been evaluated by $16 \mathrm{~S}$ rDNA and 23S rDNA sequencing, was isolated from spontaneously acidified tofu and was found to be non-toxic and nonhyper-susceptible, indicating that it can increase the antioxidant activities of fermented food sources. ${ }^{29}$ Owing to its superior capability to increase peptide contents and its safety and health benefits, L. amylolyticus L6 was determined as a good microbial source for $D$. aphyllum solid-state fermentation.

\subsection{Analysis of protease activity}

As shown in Fig. 1B, the activity of total, acid, neutral, and alkaline proteases were evaluated at different fermentation times. For the initial $48 \mathrm{~h}$ fermentation, all protease activities increased, after which time all protease activities decreased to different degrees. The activity of alkaline protease continuously increased until $60 \mathrm{~h}$ of fermentation and then steadily decreased. Therefore, the time point for optimum fermentation was approximately $48 \mathrm{~h}$. The dynamic regulation of protease activities was in accordance with the content variation of peptides, as shown in Fig. 1C; the highest yield of peptides was achieved at approximately $48 \mathrm{~h}$, indicating that peptide quantity influences protease activity. Moreover, throughout fermentation, the activity of neutral protease was nearly 2 times $(p<0.05)$ that of alkaline and acid enzyme activity, indicating that neutral protease significantly contributes to the production of peptides during fermentation. Importantly, alkaline and acidic enzyme activities were also high at above $200 \mathrm{U} \mathrm{g}^{-1}$, demonstrating the synergic effects of using three types of proteases to generate peptides during fermentation. 
A

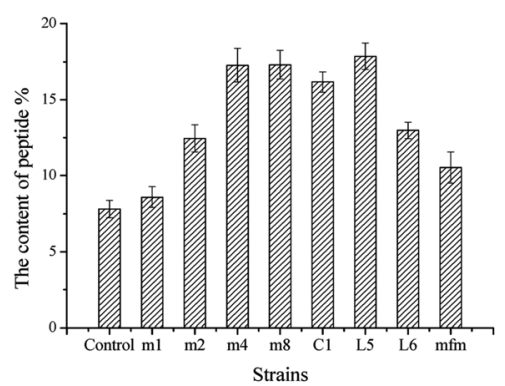

B

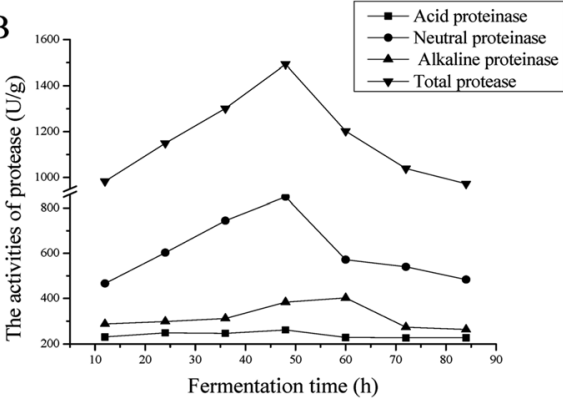

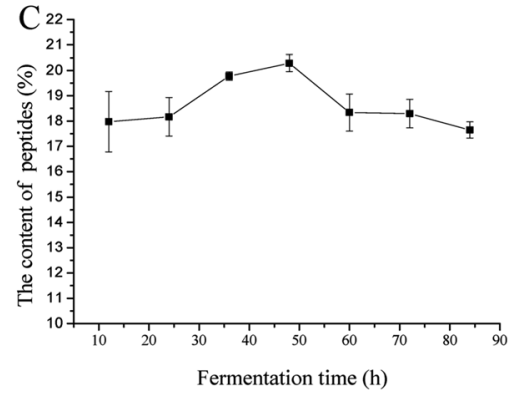

Fig. 1 (A) Extraction yield of DA-P after 8 Lactobacillus stains were used in solid-state fermentation from $D$. aphyllum. The 8 strains of Lactobacillus were Lactobacillus harbinensis (m1), Lactobacillus mucosae 1 (m2), Lactobacillus fermentum 1 (m4), Lactobacillus casei (m8), Lactobacillus rhamnosus (C1), Lactobacillus amylolyticus 5 (L5), Lactobacillus amylolyticus 6 (L6), and Lactobacillus acidophilus (mfm). The unfermented group was used as the control. (B) Activities of total protease, acid proteinase, neutral proteinase, and alkaline proteinase in fermented cultures containing DA-P at different times during $L$. amylolyticus $L 6$ solid-state fermentation from $D$. aphyllum. The extracted yield of DA-P at different fermented times (C) during L. amylolyticus L6 solid-state fermentation from D. aphyllum. Data are the mean \pm standard deviations of three independent experiments.

\subsection{Fermentative optimization}

Single-factor experiments showed that the ratio of material to solvent, inoculum size, and fermentation time significantly influenced peptide yield during fermentation (results not shown). A Box-Behnken design of RSM was developed to optimize the fermentation conditions of DA-P from D. aphyllum and the final predictive equation was obtained by eliminating insignificant factors as shown below:

$$
\begin{gathered}
R_{1}=14.96+1.38 A+2.01 B+0.83 C+1.66 A B-1.41 A C- \\
1.39 B C-2.05 A^{2}
\end{gathered}
$$

where $A$ was the ratio of material to solvent $\left(\mathrm{g} \mathrm{mL}^{-1}\right) ; B$ was inoculum size (\%); $C$ was fermentation time (h).

The optimum fermentation conditions for DA-P from D. aphyllum were a material-to-solvent ratio of $1: 4.775$, inoculum size of $21.88 \%$, and fermentation time of $46.02 \mathrm{~h}$, with a predicted result of $18.89 \%$. A ratio of material to solvent of $1: 4(\mathrm{w} / \mathrm{v})$, inoculum size of $21 \%$, and time $46 \mathrm{~h}$ were selected to

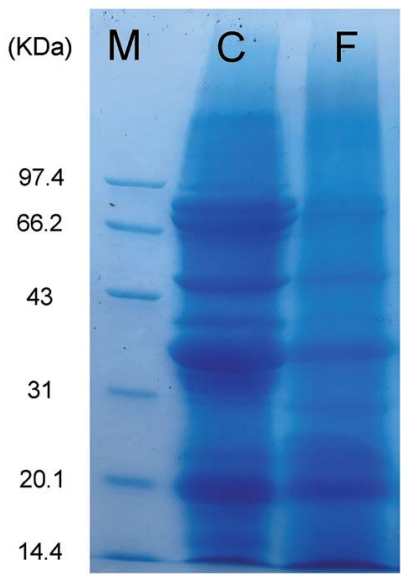

Fig. 2 SDS-PAGE of DA-P in Lactobacillus amylolyticus L6 solid-state fermentation from $D$. aphyllum. $M$ - protein marker; $C$ - prior to fermentation; $\mathrm{F}$ - after fermentation. validate the RSM model. The yield of extracting DA-P after fermentation was $18.23 \pm 0.046 \%$, which agreed with the predicted result.

\subsection{SDS-PAGE}

The molecular weight $\left(M_{\mathrm{w}}\right)$ distributions of polypeptides before and after solid-state fermentation with $L$. amylolyticus L6 were determined through SDS-PAGE. As shown in Fig. 2, the standard $M_{\mathrm{w}}$ bonds are labeled as the M-band. Comparison of before (C-band) and after (F-band) fermentation revealed that the C-band mainly consisted of molecules sized approximately $31 \mathrm{kDa}$ and higher, indicating that high- $M_{\mathrm{w}}$ polypeptides were present before fermentation, particularly major protein bands at approximately $80,68,48$, and $37 \mathrm{kDa}$. The intensity of high$M_{\mathrm{w}}$ bands was reduced and the major $M_{\mathrm{w}}$ bands were below 31 $\mathrm{kDa}$ and primarily below $20 \mathrm{kDa}$, indicating that small molecules were successfully generated during fermentation. ${ }^{25}$

\subsection{Concentration and identification of the peptide in DA-P fractions}

The DA-P peptide subjected to the ultrafiltration processes had a peptide content of $83.91 \pm 1.71 \%$. After ultrafiltration processes, the peptide percentage yields of its $<1 \mathrm{kDa}$ fraction was $45.84 \pm 1.37 \%, 1-3 \mathrm{kDa}$ fraction was $32.44 \pm 2.78 \%$, 3-5 $\mathrm{kDa}$ fraction was $3.22 \pm 0.81 \%$ and $>5 \mathrm{kDa}$ fraction was $2.70 \pm$ $0.45 \%$. These data suggest that mainly low molecular weight peptides existed in DA-P fractions.

Amino acid composition was one of the factors influencing the antioxidant activity of peptides. ${ }^{30}$ Data on the total and free amino acid composition of DA-P before ultrafiltration and its four ultrafiltration fractions is shown in Table 1 . The percentage of total amino acids in DA-P peptide sample was the highest, followed by the $<1 \mathrm{kDa}$ fraction. The sum of amino acids in the other 3 fractions was higher than $40 \mathrm{~g} / 100 \mathrm{~g}$. In addition, the percentage of free amino acid in $<1 \mathrm{kDa}$ DA-P fraction were as high as $26.22 \pm 3.79$. Since quantitative of antioxidative free amino acid existed in that fraction, we inferred that $<1 \mathrm{kDa}$ DA-P 


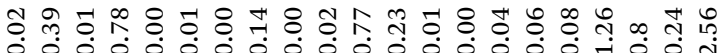
$H+H+H+H+H+H+H+H+H+H+H+H+H+H+H$

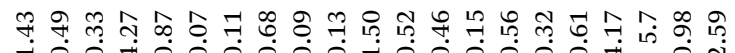

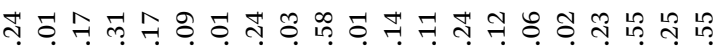
- $\dot{0}$ $H+H+H+H+H+H+H+H+H+H+H+H+H+H+H$ ț

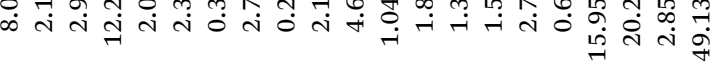

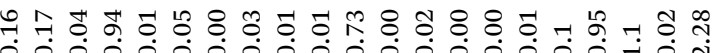
$H+H+H+H+H+H+H+H+H H H+H+H+H+H$ ๓

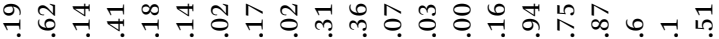

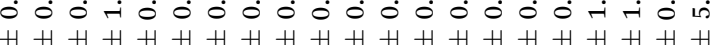

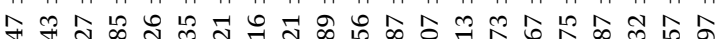
获

t艹 $H+H H H H H H H H H H H H H H H H+H H$

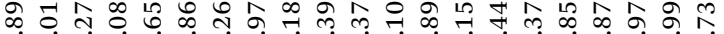

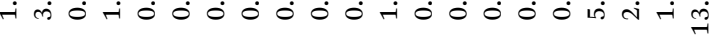

늠 OO

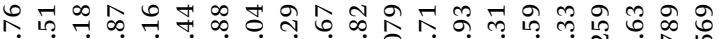

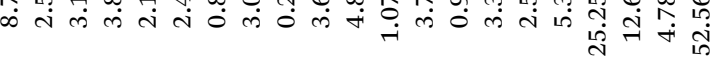

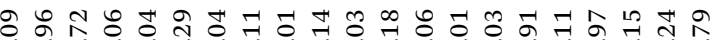

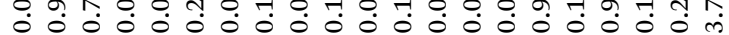
$H+H+H+H+H+H+H+H+H+H+H+H+H$

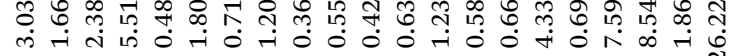

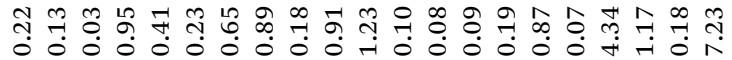

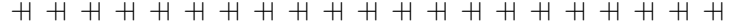

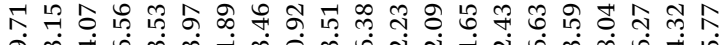
के में

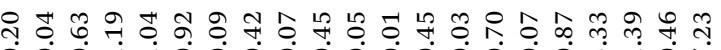
○ $H H+H H H+H H+H H H H H H+H+H$ H H

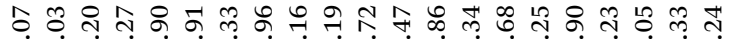

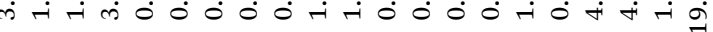

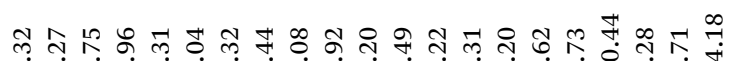

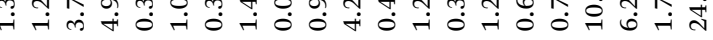
$H+H+H+H+H+H+H+H H+H+H+H+H+H$

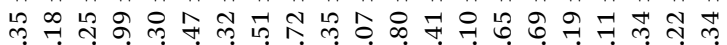

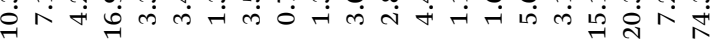


Table 2 Peptides identified by HPLC/MSMS in <1 kDa DA-P fractions

\begin{tabular}{llll}
\hline $\begin{array}{l}\text { Retention time } \\
(\mathrm{min})\end{array}$ & $\begin{array}{l}\text { Charged ion } \\
(\mathrm{m} / \mathrm{z})\end{array}$ & $\begin{array}{l}\text { Molecular } \\
\text { mass }(\mathrm{Da})\end{array}$ & Sequence \\
\hline 0.89 & 527.1575 & 526.1502 & Asp-Tyr-Asp-Asp \\
0.99 & 527.1575 & 526.1502 & Asp-Asp-Asp-Tyr \\
1.96 & 389.1749 & 388.1676 & Asn-Gly-Ala-Gln \\
1.99 & 373.1838 & 372.1765 & Trp-Pro-Ala \\
2.15 & 349.1819 & 348.1746 & Met-Ala-Lys \\
2.20 & 349.1832 & 348.1759 & Arg-Ser-Ser \\
2.22 & 411.1198 & 410.1125 & Trp-Cys-Cys \\
2.27 & 373.1840 & 372.1767 & Pro-Trp-Ala \\
2.30 & 451.1575 & 450.1502 & Asn-Gln-Cys-Ser \\
2.34 & 530.3299 & 529.3226 & Glu-Arg-Ile-Leu \\
2.58 & 437.2354 & 436.2317 & Ala-Val-Thr-Phe \\
2.61 & 411.1992 & 410.1919 & Thr-Gly-Pro-His \\
2.76 & 481.2626 & 480.2553 & Phe-Leu-Thr-Thr \\
3.02 & 569.3135 & 568.3062 & Arg-Glu-His-Lys \\
3.24 & 575.2062 & 574.1989 & Asp-Asp-Tyr-Tyr \\
3.50 & 355.1718 & 354.1645 & Glu-Arg-Arg-His \\
3.74 & 495.1831 & 494.1758 & Asn-Arg-Cys-Cys \\
4.26 & 379.1307 & 378.1234 & Met-Gly-Asp-Gly \\
7.53 & 431.2760 & 430.2687 & Ala-Lys-Arg-Gly \\
7.63 & 409.1606 & 408.1533 & Ala-Met-Met-Gly \\
8.01 & 437.1909 & 436.1836 & Met-Leu-Cys-Ala \\
& & &
\end{tabular}

fraction may have had optimal antioxidant activity. Hydrophobic amino acids (HAAs), including Ala, Val, Ile, Leu, Tyr, Phe, Try, Pro, Met, and Cys, were reported to increase the solubility of peptides in lipids, resulting in the entry into target organs through hydrophobic associations or promoting relevant interaction with free radicals. ${ }^{31}$ In our study, the $<1 \mathrm{kDa}$ and 1-3 kDa fractions had high amino acid levels, indicating that those fractions may have high antioxidant activity in the DPPH free radical scavenging assay, which is more suited for samples with lipophilic antioxidants or those with a high lipid content. ${ }^{32}$ Furthermore, the $<1 \mathrm{kDa}$ and $1-3 \mathrm{kDa}$ fractions contained higher levels of terms of negatively charged amino acids (NCAAs) and aromatic amino acids (AAAs), than the large molecular weight fractions. These amino acids have been proved to enhance the potency of radical scavenging activities owing to the abundance of their electrons that can stabilize electron-deficient radicals and then quench free radicals. ${ }^{33}$ Therefore, low molecular weight DA-P fractions are able to donate abundant protons than large molecular weight fractions, thereby leading to high free radical scavenging capability. In general, the high level of essential amino acids in all samples indicated that the DA-P peptide and its four fractions have high nutritional quality and optimal antioxidant activity.

High resolution mass spectrometer, that is able to low the errors availably, is one of the effective instrument to characterize the sequences of polypeptides especially peptide in complex matrix. Under ESI-MS/MS conditions, normally the polypeptide will be protonated and the fragmentation will start at the amide bonds. Ions of $\mathrm{b}$ and $\mathrm{y}$ are the major fragment ions when the collision energy is below $200 \mathrm{eV}$ due to the slight effects of low energy on breaking the chemical bonds in side chains..$^{34}$ In terms of peptide identification, the ions of a, b, c, x, $\mathrm{y}, \mathrm{z}$ and $\mathrm{a}, \mathrm{b}, \mathrm{c} / \mathrm{x}, \mathrm{y}, \mathrm{z}-17 / 18\left(-\mathrm{NH}_{3} /-\mathrm{H}_{2} \mathrm{O}\right)$ are the meaningful MS/ MS data to determine the peptide characterization through processing the de novo sequencing by the Biolynx peptide sequencer. $^{35,36}$ In our study, HPLC-MS/MS was carried out to determine the sequences of peptides in $<1 \mathrm{kDa}$ fraction and the results were performed in Table 2. In general, 21 types of peptide were identified in DA-P $<1 \mathrm{kDa}$ fractions, which molecular mass were all in the range from 300 to $600 \mathrm{Da}$. The small molecular peptides contained various antioxidative amino acids including NCAAs, AAAs and HAAs.

\subsection{Free radical scavenging ability of DA-P fractions}

Assays for assessing antioxidant capability are classified into two methods based on the different types of chemical reactions used. One method is based on hydrogen atom transfer, such as total radical trapping antioxidant parameters and oxygen radical absorbance capacity. The other method is based on electron transfer and includes FRAP, ABTS, and DPPH radicalscavenging assays. ${ }^{3}$ Hydrogen atom transfer-based reactions are related to radical chain-breaking antioxidant capability; hence, electron transfer-based assays are typically used to evaluate the antioxidant capability of peptides, which act as probes for monitoring reactions and indicate reaction endpoints. ${ }^{37}$ In our study, three traditional electron transfer-
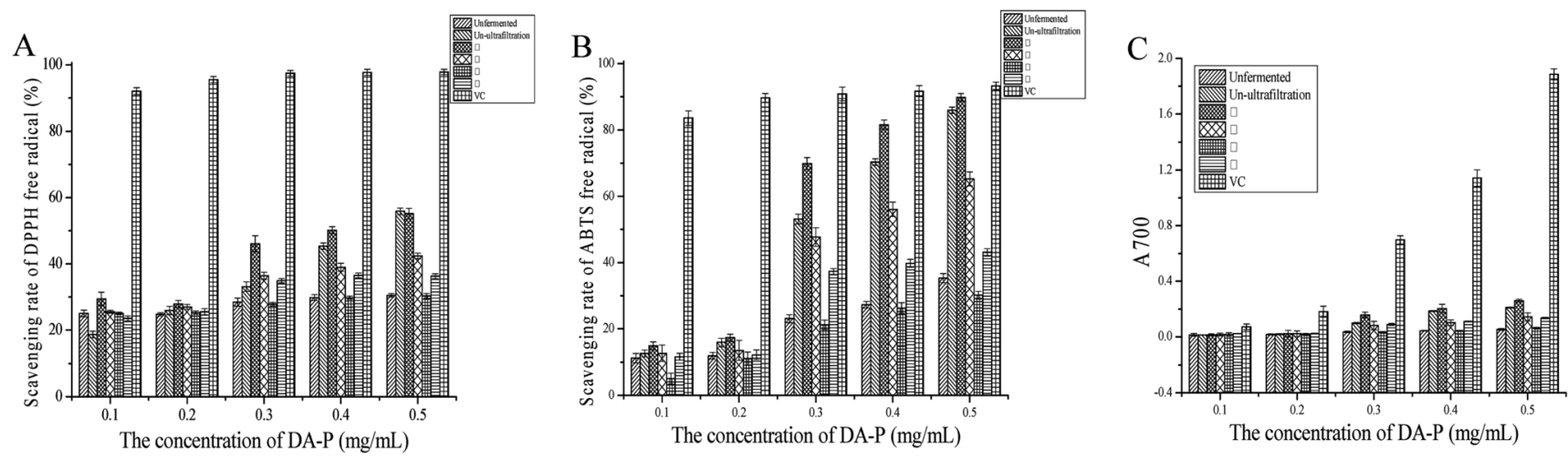

Fig. 3 Ability of DA-P of different molecular weight fractions (I-IV are $<1,1-3,3-5$, and $>5 \mathrm{kDa}$, respectively) to scavenge free radicals of (A) DPPH radical scavenging activity and (B) ABTS radical scavenging activity and (C) the ferric ion reducing antioxidative power. Unfermented and VC groups were the control and positive control groups, respectively. Data are mean \pm standard deviations of three independent experiments. 
based assays were performed for DA-P before and after fermentation, as well as fractions with different ranges of molecular weights including $<1,1-3,3-5$, and $>5 \mathrm{kDa}$ after ultrafiltration; the results are shown in Fig. 3. For all sample concentrations, antioxidant activity changed in a dosedependent manner. The scavenging rate of most concentrations was higher in the fermented groups than in the unfermented groups, indicating that during L. amylolyticus L6 fermentation, proteolytic enzymes produced by the microbial populations efficiently hydrolyzed the protein into strong antioxidant peptides and free amino acids. ${ }^{12}$ Additionally, the scavenging rate of the before-ultrafiltration groups was generally higher than that of the after-ultrafiltration fractions with molecular weights of $1-3,3-5$, and $>5 \mathrm{kDa}$. These results indicate that maybe the constituent peptides in these molecular weight groups were mostly negatively charged and had synergistic effects. ${ }^{38}$

In DPPH free radical scavenging assay, a stable centered nitrogen lipophilic free radical existed in DPPH. In the presence of a hydrogen-donating antioxidant, the reduction of DPPH free radicals would occur by inducing non-radical formation with DPPH binding hydrogen atoms. ${ }^{39,40}$ The mechanism of ABTS free radical scavenging assay is similar to that of DPPH radical scavenging assay, both based on single electron transfer. ${ }^{41}$ As shown in Fig. 3A and $\mathrm{B}$, the scavenging rate of the $<1 \mathrm{kDa}$ fraction was higher than those of the parent proteins and before-ultrafiltration peptides, possibly because released lowmolecular weight peptides and amino acids served as extra sources of electrons and protons. ${ }^{42}$ Yang et al. reported that steric structure and molecular weight of the peptides, rather than their antioxidant amino acid content, might play an important role in scavenging $\mathrm{DPPH}$ radicals, which was consistent with our findings. ${ }^{43}$ In terms of reducing power assay, the reduction of $\mathrm{Fe}^{3+}$ or ferricyanide complex to $\mathrm{Fe}^{2+}$ is carried out in the presence of a reductant, when evaluating which compounds in the extract samples are electron donors to reduce the oxidized intermediates of lipid peroxidation, and act as primary and secondary antioxidants. ${ }^{\mathbf{1 0}}$ It was previously reported that different activities of peptides fractions were mainly because of different amino acid side-chain groups, since electron-dense areas are exposed as hydrolysis progresses, and electron donors convert free radicals into more stable products that terminate the radical chain reaction. ${ }^{\mathbf{1 0 , 4 4}}$ Therefore, we can infer that the ferric reducing power depends on fermentation patterns and DA-P sizes. A greater ability to donate electrons was observed for fraction $<1 \mathrm{kDa}$, which is concurrent with pervious results. ${ }^{42}$

\subsection{Attenuation of erythrocyte hemolysis by DA-P}

The $<1$ kDa DA-P fraction displayed the strongest chemical antioxidant ability was thus was further analyzed through AAPH-induced oxidative stress assays to evaluate human erythrocyte hemolysis. The hemolysis inhibition rate was related to the type and concentration of the sample, as shown in Fig. 4A. The inhibition rate of the control group on human erythrocyte hemolysis was the highest at $96.89 \pm 0.11$; thus, erythrocytes existed in the absence of antioxidative stress, in which the corresponding red cell membrane showed a normal biconcave discoid morphology, according to SEM analysis (Fig. 5A). The inhibition rate following treatment with the $<1$ $\mathrm{kDa}$ DA-P fraction was similar to that of the control, indicating that the peptide was nontoxic and did not influence erythrocyte hemolysis. When treated with AAPH, oxidative stress on erythrocyte led to hemolysis with the lowest inhibition rate $(28.4 \pm$ $0.68 \%$ ); the normal profile was lost and spiny structures formed on the surface, as shown in Fig. 5B. During erythrocyte hemolysis at $37{ }^{\circ} \mathrm{C}$, alkyl radicals are generated through decomposition by AAPH; through the contribution of oxygen, peroxyl radicals form and cause lipid peroxidation and the loss of membrane integrity. ${ }^{17}$ Pretreatment with a gradient concentration of $M_{\mathrm{W}}<1 \mathrm{kDa}$ DA-P fraction showed greater inhibition of hemolysis of AAPH-induced erythrocytes in a dose-response manner. The protective effect of $M_{\mathrm{w}}<1 \mathrm{kDa}$ DA-P fraction on AAPH-induced morphological improvement in human
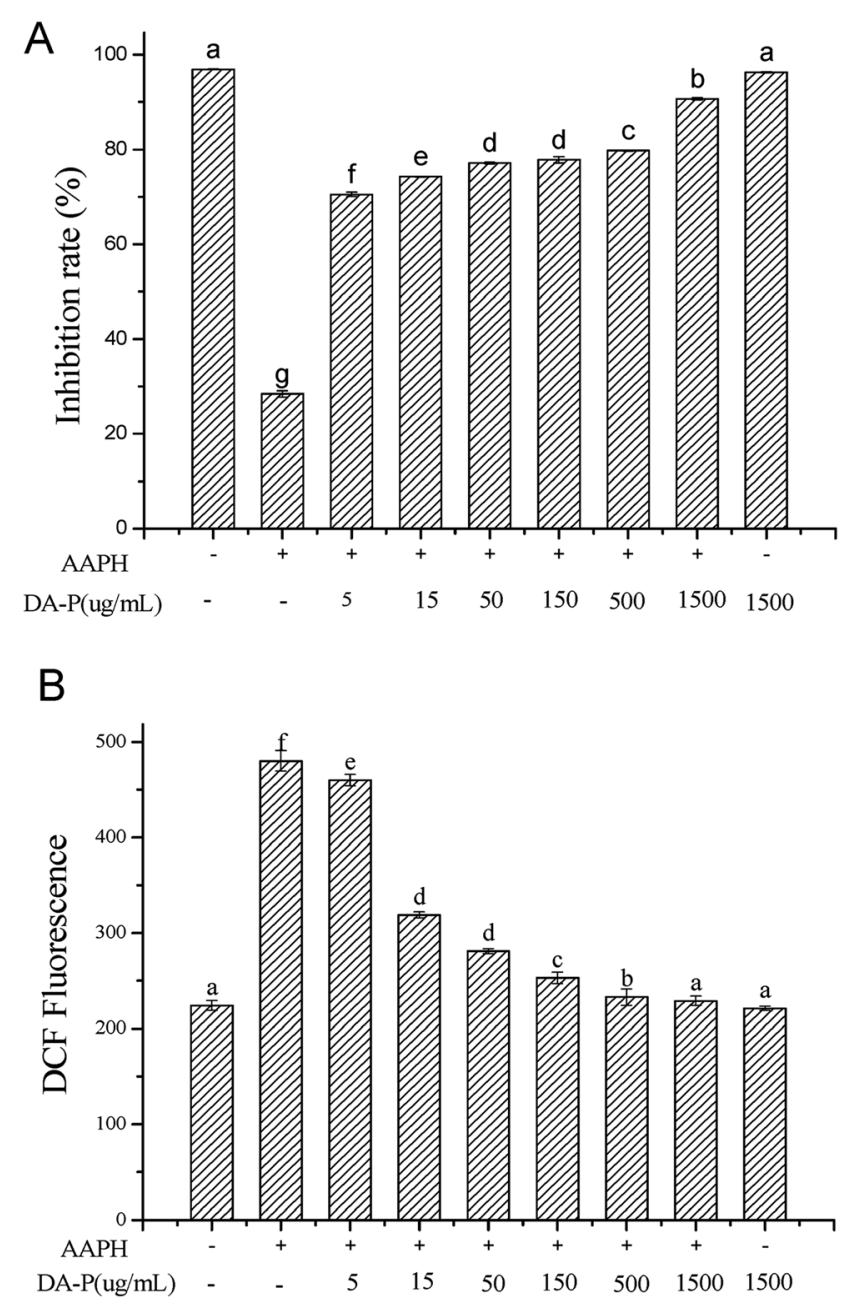

Fig. 4 (A) Protective effects of DA-P fraction (molecular weight $<1$ $\mathrm{kDa}$ ) on $\mathrm{AAPH}$-induced erythrocyte hemolysis activity. (B) Inhibitory activity of DA-P fraction (molecular weight $<1 \mathrm{kDa}$, concentration of 0-1.5 $\mathrm{mg} \mathrm{mL}^{-1}$ ) on AAPH-induced ROS overexpression in human erythrocytes. AAPH alone ( $200 \mathrm{mM})$ was used as the positive control group. Data are mean \pm standard deviations of three independent experiments. 

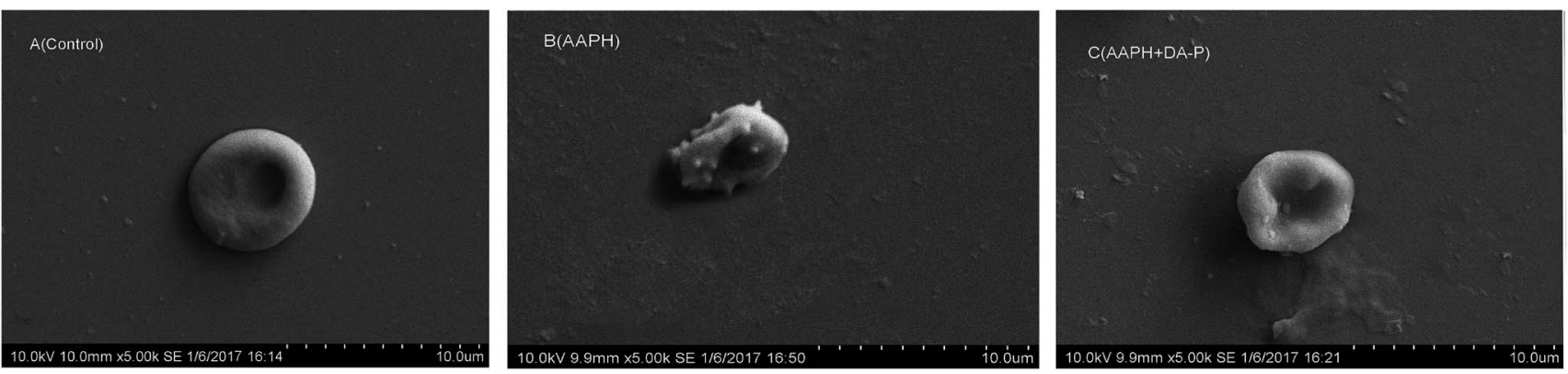

Fig. 5 SEM micrographs of normal samples (A), AAPH-treated erythrocyte samples (B) and erythrocytes pre-incubated with DA-P fraction (molecular weight $<1 \mathrm{kDa}$ ) prior to AAPH treatment (C).

erythrocytes was confirmed through SEM imaging, with membrane damage significantly reduced in cells pretreated with $1.5 \mathrm{mg} \mathrm{mL}^{-1}$ of the $<1 \mathrm{kDa}$ DA-P fraction before the addition of AAPH (Fig. 5C).

Antioxidants can directly act as free radical scavengers or improve antioxidant systems. In this study, both antioxidative mechanisms were evaluated, including non-enzymatic and enzymatic antioxidant systems.

DCFH-DA, a fluorescein-labeled dye, is non-fluorescent and can cross the plasma membrane into the cytoplasm and become hydrolyzed to form DCF, a highly fluorescent compound, by nonspecific esterases..$^{15}$ Therefore, under oxidative stress, fluorescence increases. In our study, by evaluating the intensity of DCF fluorescence, erythrocyte intracellular ROS generation was prevented by $M_{\mathrm{w}}<1$ kDa DA-P fraction antioxidative protective effects, as shown in Fig. 4B. Without treatment, DCF fluorescence in the control group showed the lowest value of $224 \pm 5.11$, while following AAPH treatment, DCF fluorescence was very high at $480 \pm 10.68$, indicating that AAPH increased oxidative stress. However, following pretreatment with different concentrations of the $<1$ kDa DA-P fraction, the intensity decreased in a dose-dependent manner. Particularly, a peptide concentration of $1.5 \mathrm{mg} \mathrm{mL} \mathrm{mL}^{-1}$ yielded the best antioxidative protection by reducing intracellular ROS generation. Because no significant difference in DCF fluorescence was observed for erythrocytes treated with the $<1 \mathrm{kDa}$ fraction alone compared with that in the control, the $<1 \mathrm{kDa}$ fraction was unable to generate ROS in erythrocytes. In summary, the free
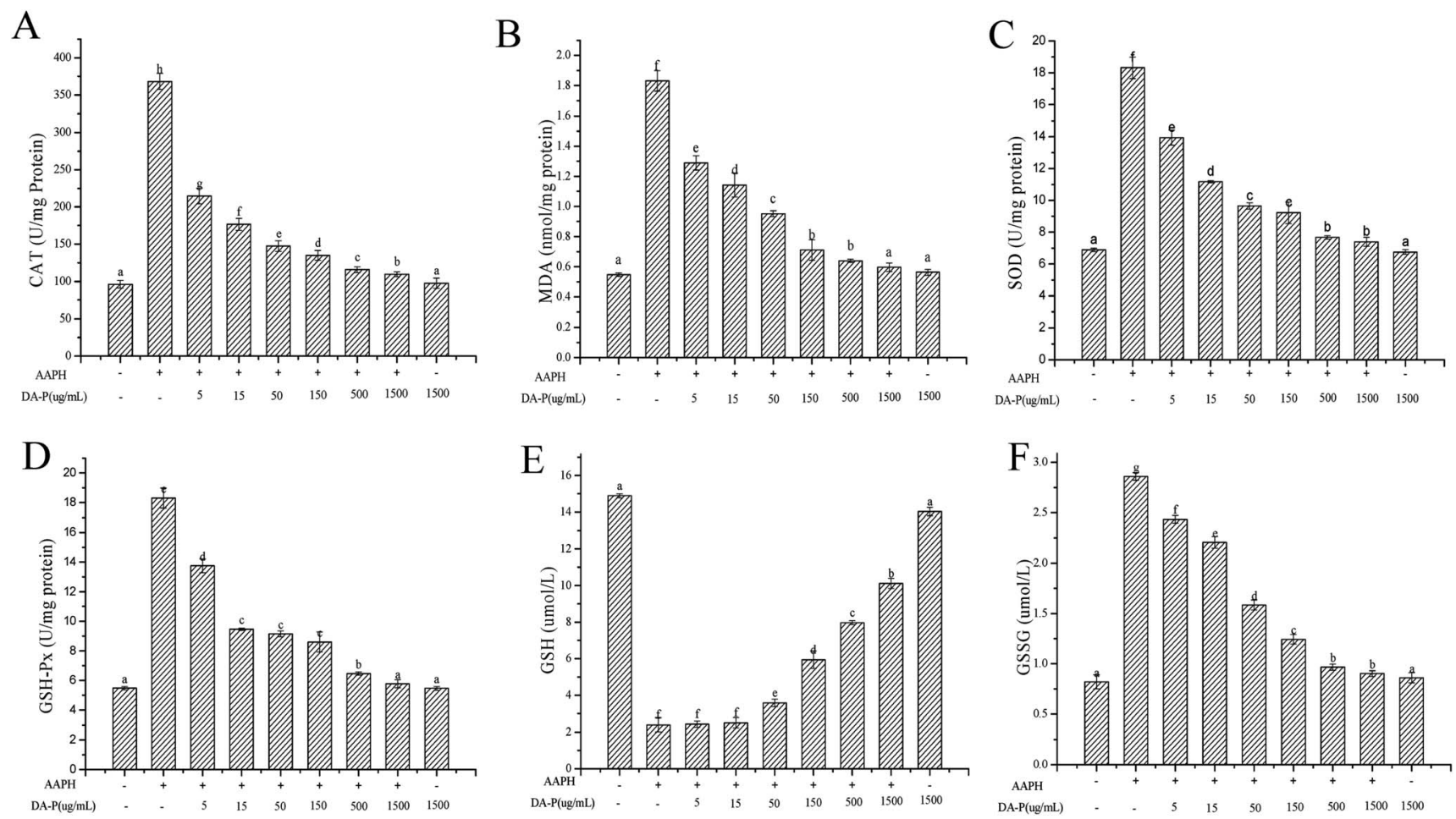

Fig. 6 Changes in CAT (A) and MDA (B) content and enzyme activities of SOD (C), GSH-Px (D), GSSG (E), and GSH (F) in human erythrocytes. Erythrocytes were pretreated with DA-P fraction (molecular weight $<1 \mathrm{kDa}$, concentration of $0-1.5 \mathrm{mg} \mathrm{mL}^{-1}$ ) for $30 \mathrm{~min}$ prior to AAPH (200 mM) treatment for $2 \mathrm{~h}$; the positive group was treated with $200 \mathrm{mM} \mathrm{AAPH}$ alone and control group was treated with $1.5 \mathrm{mg} \mathrm{mL}-1$ DA-P alone. Data are mean \pm standard deviations of three independent experiments. 
radical scavenger $<1 \mathrm{kDa}$ DA-P fraction inhibited intracellular AAPH-induced ROS generation in erythrocytes in a dosedependent manner.

Excess ROS generation can cause lipid peroxidation, which directly increases MDA levels. Excess MDA negatively affects tumor promotion, cellular metabolism disruption, and cell membrane dysfunction. In our study, the MDA level is shown in Fig. 6B. The lowest level of MDA was $0.548 \pm 0.011 \mathrm{~nm} \mathrm{mg}^{-1}$ protein in the control group without peptide or AAPH treatment, whereas under AAPH-induced oxidative stress, the MDA level was $1.831 \pm 0.068 \mathrm{~nm} \mathrm{mg}^{-1}$ protein. It is not surprising that $M_{\mathrm{w}}<1 \mathrm{kDa}$ DA-P fraction decreased the MDA level in a dose-dependent manner and was similar to the MDA level in the control group when the concentration of $M_{\mathrm{w}}<1 \mathrm{kDa}$ fraction was $1.5 \mathrm{mg} \mathrm{mL}^{-1}$. Additionally, the MDA level in the $M_{\mathrm{w}}<1 \mathrm{kDa}$ fraction alone group ( $0.563 \pm 0.02 \mathrm{~nm} \mathrm{mg}^{-1}$ protein), which was similar to that in the control, indicated that $M_{\mathrm{w}}<1 \mathrm{kDa}$ fraction alone did not increase MDA levels. In general, $M_{\mathrm{w}}<1 \mathrm{kDa}$ DA-P fraction can prevent AAPH-induced MDA accumulation by decreasing ROS generation.

To determine whether the enzymatic antioxidative system is present in erythrocytes, the activities of antioxidant enzymes including SOD, CAT, and GPx were evaluated. As shown in Fig. 6, the groups treated with AAPH alone showed very high enzyme activities, which were $368.02 \pm 10.68 \mathrm{U} \mathrm{mg}^{-1}$ protein for CAT, $18.31 \pm 0.68 \mathrm{U} \mathrm{mg}^{-1}$ protein for SOD, and $18.31 \pm 0.16 \mathrm{U}$ $\mathrm{mg}^{-1}$ protein or GPx, while the activities of CAT (Fig. 6A), SOD (Fig. 6C), and GPx (Fig. 6D) decreased steadily with increasing concentrations of $<1 \mathrm{kDa}$ DA-P fraction in a dose-dependent manner. Enzyme activities in the control groups were the lowest, with values of $96.05 \pm 5.11 \mathrm{U} \mathrm{mg}^{-1}$ protein for CAT, 6.89 $\pm 0.11 \mathrm{U} \mathrm{mg}^{-1}$ protein for SOD, and $5.48 \pm 0.12 \mathrm{U} \mathrm{mg}^{-1}$ protein for GPx. In addition, enzyme activity levels in the group pretreated with $M_{\mathrm{w}}<1 \mathrm{kDa}$ fraction alone were similar to those of the control, indicating that the $<1 \mathrm{kDa}$ DA-P fraction itself did not increase oxidative-related enzyme activities. In conclusion, $M_{\mathrm{w}}<1 \mathrm{kDa}$ DA-P fraction modulated intracellular antioxidant enzyme activity, particularly at high concentrations.

In the erythrocyte intracellular enzyme system, CAT converts hydrogen peroxide into oxygen and water. ${ }^{6}$ SOD catalyzes the conversion of highly reactive superoxide anion to less reactive oxygen and hydrogen peroxide through dismutation. Excess hydrogen peroxide can be reduced by CAT and GPx to prevent hydrogen peroxide from being converted into more active species such as hydroxyl radicals, which promote cell death. ${ }^{\mathbf{1 6 , 1 7}}$ Moreover, GPx catalyzes the conversion of glutathione from the reduced form GSH to the oxidized form GSSH. Circulating GPx can protect erythrocytes from oxidative damage by increasing GSH levels (Fig. 6E) and decreasing GSSG levels (Fig. 6F) after pretreatment of erythrocytes with the $>150 \mu \mathrm{g} \mathrm{mL}^{-1}<1 \mathrm{kDa}$ DA$P$ fraction.

There are two mechanisms involved in maintaining antioxidative effects during erythrocyte hemolysis. First, antioxidants form a protective membrane with an electronegative outer surface around erythrocytes without promoting antioxidase and gene expression, preventing contact between free radicals and the plasma membrane to inhibit ROS generation. ${ }^{\mathbf{1 7}}$ Second, antioxidants directly quench the cellular antioxidant system. ${ }^{6}$ Since DA-P was purified to low-molecular weight peptide fractions $<1 \mathrm{kDa}$ via ultrafiltration, which functioned as a free radical scavenger in chemical oxidative reactions, we infer that the low-weight DA-P peptide fraction passed through the erythrocyte membrane and directly inhibited ROS generation and MDA formation induced by AAPH and also regulated

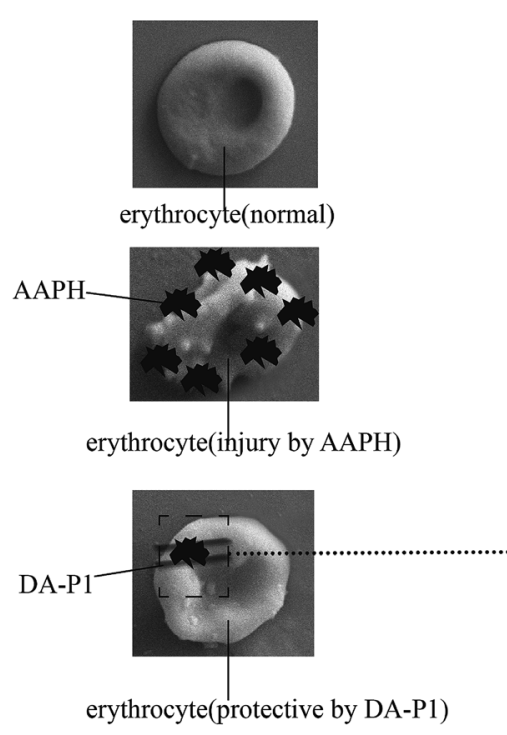

Fig. 7 Possible intracellular antioxidant-detoxifying mechanisms of DA-P1 attenuating AAPH-induced oxidative stress by inhibiting ROS generation. 
intracellular antioxidant enzyme activity. The details of the protective effects of $<1 \mathrm{kDa}$ DA-P fractions during oxidative erythrocyte hemolysis induced by AAPH are shown in Fig. 7.

\section{Conclusions}

In this study, antioxidative peptides were extracted from $D$. aphyllum after optimizing Lactobacillus solid-state fermentation. After identifying the optimum strain for fermentation as $L$. amylolyticus L6, an RSM model was used to optimize fermentation conditions, which were a material-to-solvent ratio of $1: 4$ $(\mathrm{w} / \mathrm{v})$, inoculum size of $21 \%$, and fermentation time of $46 \mathrm{~h}$. DA$\mathrm{P}$ yield obtained under the optimized fermentation conditions was $18.23 \pm 0.046 \%$. Analysis of amino acid composition indicated high antioxidative potential of the low molecular weight DA-P fractions and HPLC-MS/MS analysis proved that 21 different types of polypeptides existed in the $<1 \mathrm{kDa}$ DA-P fraction. Through the ET-based assay, the $<1 \mathrm{kDa}$ DA-P fraction showed satisfactory antioxidative abilities in chemicalbased antioxidative assays, including DPPH and ABTS free radical scavenging assays and the reducing power assay, in which that fraction could scavenge free radicals to prevent oxidation. Changing the concentration of DA-P altered antioxidative capabilities because of the increasing antioxidative peptide content, with the $<1 \mathrm{kDa}$ DA-P fraction yielding the best results. According to the results of the human erythrocyte AAPH-induced hemolysis assay, the $<1$ kDa DA-P fraction quenched the intracellular antioxidant system by inhibiting ROS generation, preventing MDA formation, and regulating cellular antioxidative enzyme activity, including SOD, CAT, and GPx. Additionally, GPx increased GSH content and decreased GSSG content. Therefore, the novel antioxidative $<1 \mathrm{kDa}$ fraction isolated from D. aphyllum after L. amylolyticus L6-solidstate optimized fermentation may be useful in functional foods and complementary medicine. This study provides a foundation for the further investigation on peptides of Dendrobium, particularly D. aphyllum.

\section{Conflicts of interest}

There are no conflicts to declare.

\section{Acknowledgements}

This study was financially supported by the Open Project Program of Science and 429 Technology Planning Project of Guangdong Province (Grant No. 2016A040402020430 and No. 2016B010121014).

\section{References}

1 A. Sila and A. Bougatef, Antioxidant peptides from marine by-products: isolation, identification and application in food systems. A review, J. Funct. Foods, 2016, 21, 10-26.

2 S. Sanjukta and A. K. Rai, Production of bioactive peptides during soybean fermentation and their potential health benefits, Trends Food Sci. Technol., 2016, 50, 1-10.
3 B. H. Sarmadi and A. Ismail, Antioxidative peptides from food proteins: a review, Peptides, 2010, 31, 1949-1956.

4 J. Dziuba, P. Minkiewicz and D. Nałęcz, Biologically active peptides from plant and animal proteins, Pol. J. Food Nutr. Sci., 1999, 8/49, 3-16.

5 N. Rajapakse, E. Mendis, W. K. Jung, J. Y. Je and S. K. Kim, Purification of a radical scavenging peptide from fermented mussel sauce and its antioxidant properties, Food Res. Int., 2005, 38, 175-182.

6 W. Liao, Z. Ning, L. Chen, Q. Wei, E. Yuan, J. Yang and J. Ren, Intracellular antioxidant detoxifying effects of diosmetin on 2,2-azobis(2-amidinopropane)dihydrochloride (AAPH)induced oxidative stress through inhibition of reactive oxygen species generation, J. Agric. Food Chem., 2014, 62, 8648.

7 M. Alaiz, M. Beppu, K. Ohishi and K. Kikugawa, Modification of delipidated apoprotein B of low density lipoprotein by lipid oxidation products in relation to macrophage scavenger receptor binding, Biol. Pharm. Bull., 1994, 17, 51.

8 J. Lee, N. Koo and D. B. Min, Reactive Oxygen Species, Aging, and Antioxidative Nutraceuticals, Compr. Rev. Food Sci. Food Saf., 2004, 3, 21-33.

9 H.-S. Hwang and J. K. Winkler-Moser, Antioxidant activity of amino acids in soybean oil at frying temperature: structural effects and synergism with tocopherols, Food Chem., 2017, 221, 1168-1177.

10 B. Moktan, J. Saha and P. K. Sarkar, Antioxidant activities of soybean as affected by Bacillus-fermentation to kinema, Food Res. Int., 2008, 41, 586-593.

$11 \mathrm{C} . \mathrm{Hu}, \mathrm{C} . \mathrm{H}$ siao, S. Huang, S. Fu, C. Lai, T. Hong, A. Hweihsien Chen and F. J. Lu, Antioxidant Activity of Fermented Soybean Extract, J. Agric. Food Chem., 2004, 52, 5735.

12 S. Ranamukhaarachchi, L. Meissner and C. Moresoli, Production of antioxidant soy protein hydrolysates by sequential ultrafiltration and nanofiltration, J. Membr. Sci., 2013, 429, 81-87.

13 D. Huang, B. Ou and R. L. Prior, The chemistry behind antioxidant capacity assays, J. Agric. Food Chem., 2005, 53, 1841.

14 L. K. Macdonaldwicks, L. G. Wood and M. L. Garg, Methodology for the determination of biological antioxidant capacity in vitro: a review, J. Sci. Food Agric., 2006, 86, 2046-2056.

15 G. Wang, Z. Lei, Q. Zhong, W. Wu, H. Zhang, T. Min, H. Wu and F. Lai, Enrichment of caffeic acid in peanut sprouts and evaluation of its in vitro effectiveness against oxidative stress-induced erythrocyte hemolysis, Food Chem., 2017, 217, 332-341.

16 J. Wang, B. Sun, Y. Cao and Y. Tian, Protection of wheat bran feruloyl oligosaccharides against free radical-induced oxidative damage in normal human erythrocytes, Food Chem. Toxicol., 2009, 47, 1591-1599.

17 M. Zhang, Z. Hong, H. Li, F. Lai, X. F. Li, Y. Tang, M. Tian and W. Hui, Antioxidant Mechanism of Betaine without Free Radicals Scavenging Ability, J. Agric. Food Chem., 2016, 64, 7921-7930. 
18 C. G. Zou, N. S. Agar and G. L. Jones, Oxidative insult to human red blood cells induced by free radical initiator AAPH and its inhibition by a commercial antioxidant mixture, Life Sci., 2001, 69, 75-86.

19 T. B. Ng, J. Liu, J. H. Wong, X. Ye, S. C. W. Sze, T. Yao and K. Y. Zhang, Review of research on Dendrobium, a prized folk medicine, Appl. Microbiol. Biotechnol., 2012, 93, 17951803.

20 X. Zhang, J. Xu, J. Wang, N. Wang, H. Kurihara, S. Kitanaka and X. Yao, Bioactive Bibenzyl Derivatives and Fluorenones from Dendrobium nobile, J. Nat. Prod., 2007, 70, 24.

21 Y. Fan, X. J. He, S. Zhou, A. Luo, T. He and Z. Chun, Composition analysis and antioxidant activity of polysaccharide from Dendrobium denneanum, Int. J. Biol. Macromol., 2009, 45, 169.

22 Y. Cui, J. König, I. Leier, U. Buchholz and D. Keppler, Hepatic uptake of bilirubin and its conjugates by the human organic anion-transporting polypeptide 2 (symbol SLC21A6), J. Biol. Chem., 2001, 276, 9626-9630.

23 C. Wang, Q. Wang and J. Tian, Optimization of enzymatic production of oligopeptides from apricot almonds meal with neutrase and N120P, Int. J. Mol. Sci., 2010, 11, 49524961.

24 E. D. N. S. Abeyrathne, H. Y. Lee, C. Jo, J. W. Suh and D. U. Ahn, Enzymatic hydrolysis of ovomucin and the functional and structural characteristics of peptides in the hydrolysates, Food Chem., 2016, $192,107$.

25 B. M. Kimatu, L. Zhao, B. Yuan, G. Ma, W. Yang, P. Fei and Q. $\mathrm{Hu}$, Antioxidant potential of edible mushroom (Agaricus bisporus) protein hydrolysates and their ultrafiltration fractions, Food Chem., 2017, 230, 58-67.

26 L. You, J. Ren, B. Yang, J. Regenstein and M. Zhao, Antifatigue activities of loach protein hydrolysates with different antioxidant activities, J. Agric. Food Chem., 2012, 60, 12324-12331.

27 Q. L. Luo, Z. H. Tang, X. F. Zhang, Y. H. Zhong, S. Z. Yao, L. S. Wang, C. W. Lin and X. Luo, Chemical properties and antioxidant activity of a water-soluble polysaccharide from Dendrobium officinale, Int. J. Biol. Macromol., 2016, 89, 219.

28 W. Liao, Y. Lu, J. Fu, Z. Ning, J. Yang and J. Ren, Preparation and Characterization of Dictyophora indusiata Polysaccharide-Zinc Complex and Its Augmented Antiproliferative Activity on Human Cancer Cells, J. Agric. Food Chem., 2015, 63, 6525.

29 Y. Fei, L. Liu, D. Liu, L. Chen, B. Tan, L. Fu and L. Li, Investigation on the safety of Lactobacillus amylolyticus L6 and its fermentation properties of tofu whey, LWT-Food Sci. Technol., 2017, 84, 314-322.

30 J. O. Onuh, A. T. Girgih, R. E. Aluko and M. Aliani, In vitro antioxidant properties of chicken skin enzymatic protein hydrolysates and membrane fractions, Food Chem., 2014, 150, 366.

31 Q. Zhao, H. Xiong, C. Selomulya, X. D. Chen, H. Zhong, S. Wang, W. Sun and Q. Zhou, Enzymatic hydrolysis of rice dreg protein: effects of enzyme type on the functional properties and antioxidant activities of recovered proteins, Food Chem., 2012, 134, 1360-1367.

32 R. N. R. T. J. Mustafa Ozgen, Modified 2,2-Azino-bis-3ethylbenzothiazoline-6-sulfonic Acid (ABTS) Method to Measure Antioxidant Capacity of Selected Small Fruits and Comparison to Ferric Reducing Antioxidant Power (FRAP) and 2,2'-Diphenyl-1-picrylhydrazyl (DPPH) Methods, $J$. Agric. Food Chem., 2006, 54, 1151-1157.

33 B. H. Sarmadi and A. Ismail, Antioxidative peptides from food proteins: a review, Peptides, 2010, 31, 1949.

34 B. Hernández-Ledesma, A. Dávalos, B. Bartolomé and L. Amigo, Preparation of antioxidant enzymatic hydrolysates from alpha-lactalbumin and betalactoglobulin. Identification of active peptides by HPLCMS/MS, J. Agric. Food Chem., 2005, 53, 588-593.

35 B. Ma, K. Zhang, C. Hendrie, C. Liang, M. Li, A. Dohertykirby and G. Lajoie, PEAKS: powerful software for peptide de novo sequencing by tandem mass spectrometry, Rapid Commun. Mass Spectrom., 2003, 17, 2337.

36 L. J. Hohmann, J. K. Eng, A. Gemmill, J. Klimek, O. Vitek, G. E. Reid and D. B. Martin, Quantification of the compositional information provided by immonium ions on a quadrupole-time-of-flight mass spectrometer, Anal. Chem., 2008, 80, 5596-5606.

37 Z. Ana, E. Mariaj and F. Ana, ORAC and TEAC assays comparison to measure the antioxidant capacity of food products, Food Chem., 2009, 114, 310-316.

38 W.-D. Chiang, M.-J. Tsou, Z.-Y. Tsai and T.-C. Tsai, Angiotensin I-converting enzyme inhibitor derived from soy protein hydrolysate and produced by using membrane reactor, Food Chem., 2006, 98, 725-732.

39 B. Yang, M. M. Zhao, J. Shi, N. Yang and Y. M. Jiang, Effect of ultrasonic treatment on the recovery and DPPH radical scavenging activity of polysaccharides from longan fruit pericarp, Food Chem., 2008, 106, 685-690.

$40 \mathrm{~J}$. H. Cummings and G. T. Macfarlane, The control and consequences of bacterial fermentation in the human colon, J. Appl. Bacteriol., 1991, 70, 443.

41 P. Wongputtisin, C. Khanongnuch, P. Pongpiachan and S. Lumyong, Antioxidant activity improvement of soybean meal by microbial fermentation, Res. J. Microbiol., 2007, 2, 577-583.

42 P. Liu, M. Zhao, Y. Cao, Y. Lu, M. Liang, Z. Huang and J. Ren, Purification and identification of antioxidant soybean peptides by consecutive chromatography and electrospray ionization-mass spectrometry, Rejuvenation Res., 2014, 17, 209-211.

43 B. Yang, H. Yang, J. Li, Z. Li and Y. Jiang, Amino acid composition, molecular weight distribution and antioxidant activity of protein hydrolysates of soy sauce lees, Food Chem., 2011, 124, 551-555.

$44 \mathrm{X}$. Wang, H. Chen, X. Fu, S. Li and J. Wei, A novel antioxidant and ACE inhibitory peptide from rice bran protein: biochemical characterization and molecular docking study, LWT-Food Sci. Technol., 2017, 75, 93-99. 